\title{
Critical Lateral-Torsional Buckling Moments of Steel Web-Tapered I-beams
}

\author{
Ioannis G. Raftoyiannis* and Theodore Adamakos
}

Department of Civil Engineering, National Technical University of Athens, Athens 15780, Greece

\begin{abstract}
This paper deals with the stability of steel web-tapered I-beams subjected to bending loads. Tapered beams can carry a maximum bending moment at a single location while in the rest of the member the moment carrying capacity is considerably lower. This results in appreciable savings in materials as well as in construction. Numerous researchers have focused on the investigation of the elastic behavior of tapered I-beams and many theoretical findings have been incorporated into the current specifications. According to Eurocode 3, the elastic critical moment is used for determining the design strength against lateral-torsional buckling (LTB) of I-beams with uniform cross-section and a number of coefficients is employed accounting for the boundary conditions, the cross-sectional geometry and the type of transverse loading, while no detailed information is given regarding non-uniform members. In this work a simple numerical approach is presented for determining the critical lateral-torsional buckling loads of web-tapered I-beams. Modification factors of the elastic critical moment with reference to the mean cross-section are given for various taper ratios. The results presented in graphical form are compared with those of previous investigations. The approach presented herein can be very easily applied for the design of tapered beams against lateral-torsional buckling.
\end{abstract}

Keywords: Elastic buckling, lateral-torsional buckling, steel profiles, web-tapered beams.

\section{INTRODUCTION}

Steel members with non-uniform cross-section are commonly used as beams in the design of various structures such as building frames, cranes, masts etc., due to the effort to minimize the total weight and subsequently the cost of the structure [1,2]. The elastic buckling of beams with nonuniform cross-section has been studied by numerous researchers. Kitipornchai \& Trahair [3] presented analytical and experimental results for tapered beams under transverse loads. Fraser [4] presented guidelines for the design of portal frames with tapered members, while Mendera [5] proceeded to the buckling strength of such members. Ermopoulos [6-9] analyzed buckling of tapered bars under bending and axial loading using the slope-deflection method, while Bradford [10] studied tapered beams subjected to unequal endmoments. Recently, Andrade et al. [11] presented a onedimensional model for studying the lateral-torsional buckling behavior of singly symmetric web-tapered cantilevers and simply supported thin-walled beams, while Zhang \& Tong [12] studied the same problem based on a new theory and the variational principle for buckling analysis. Finally, Khelil \& Larue [13] presented simple solutions for the lateral buckling of beams with restrained flanges employing the Galerkin method. Many other researchers not mentioned herein have studied the tosinal-flexural buckling problem of columns with variable cross-section under both axial and transverse loads.

*Address correspondence to this author at the Department of Civil Engineering, National Technical University of Athens, Athens 15780, Greece; Tel: +30-210-7722454; Fax: +30-210-7722482;

E-mail: rafto@central.ntua.gr
A stability analysis of the entire structure is required when designing such members according to Timoshenko \& Gere [14], which leads to the determination of the exact buckling load of each member as well [15] according to the provisions of Eurocode 3. The main loading to the beams consists of bending moments and shear due to transverse loads or of end-moments. After determining the elastic critical moment of the beam, one may proceed to the design of the member against lateral-torsional buckling by following the provisions of Eurocode 3 [15] and computing the LT buckling strength. This step involves the use of the reduction factor $\chi_{\mathrm{LT}}$, which is out of the scope of this work.

Tapered beams are manufactured either from hot-rolled profiles cut in the web lengthwise and re-welded in a special arrangement or from assembling steel plates with fillet welds. As a result, the produced beam may also suffer from distortional buckling [3] and hence, the so-called taper ratio that is the ratio of the web heights at the two ends of the beam is of significant importance in our study. For the above reason and in order to avoid distortional buckling of the cross-section the taper ratio is kept within a reasonable range and thus, distortional buckling is not considered herein.

In the present study, the influence of the taper ratio and cross-sectional geometry on the stability of non-uniform steel members that are subjected to bending loads is thoroughly investigated. The effect of shear forces is considered negligible. The problem is studied by focusing on webtapered I-beams with build-up cross-sections that are usually met in steel structures. The methodology is based on the formulation of the total potential energy and the numerical solution for buckling of beams with constant or variable cross-section [16]. The beams are considered simply sup- 
ported in bending, while other boundary conditions can be easily dealt with the approach proposed herein. Some characteristic model cases are also analyzed via the finite element method [17] and the corresponding results are presented for comparison along with the analytical ones in the form of diagrams.

More specifically, in this paper special emphasis is given on analytical models which provide qualitative results of buckling loads for tapered beams and establish the effect of properties' variation on their buckling behavior. This is very helpful for the designer who can easily apply the proposed technique to compute with reasonable accuracy the elastic critical moments and hence, the load carrying capacity of such types of beams. The effect of taper ratio on the buckling strength of such beams is not dealt with in detail in the bibliography. Employment of a detailed finite element analysis serves herewith for verification purposes only and both analytical and numerical results correlate with reasonable accuracy. Then, the analytical results for critical loads (obtained via the Rayleigh-Ritz method) referring to perfect members can be employed to determine the corresponding strength of the member by using the reduction factor $\chi_{\mathrm{LT}}$.

\section{ANALYTICAL MODEL}

Consider the web-tapered I-beam with length $\ell$ shown in Fig. (1). The beam has a doubly symmetric cross-section with variable height $h(x)$, while the width $b$ of the flanges and the thickness $t_{w}$ of the web and $t_{f}$ of the flanges are constant along the length of the beam. The boundary conditions regarding the end-rotations of the tapered beam due to torsion, which have been considered herein, are shown in Fig. (2). These boundary conditions apply simultaneously with the ones corresponding in bending. More specifically, if $\theta(x)$ is the angle of twist along the length of the tapered beam due to lateral-torsional buckling, the simply supported case corresponds to fixed rotation and free warping at the beam-end, while the fixed case corresponds to fixed rotation and fixed warping. The free condition corresponds to free rotation and warping of the beam-end and applies only to the case of a cantilever beam.

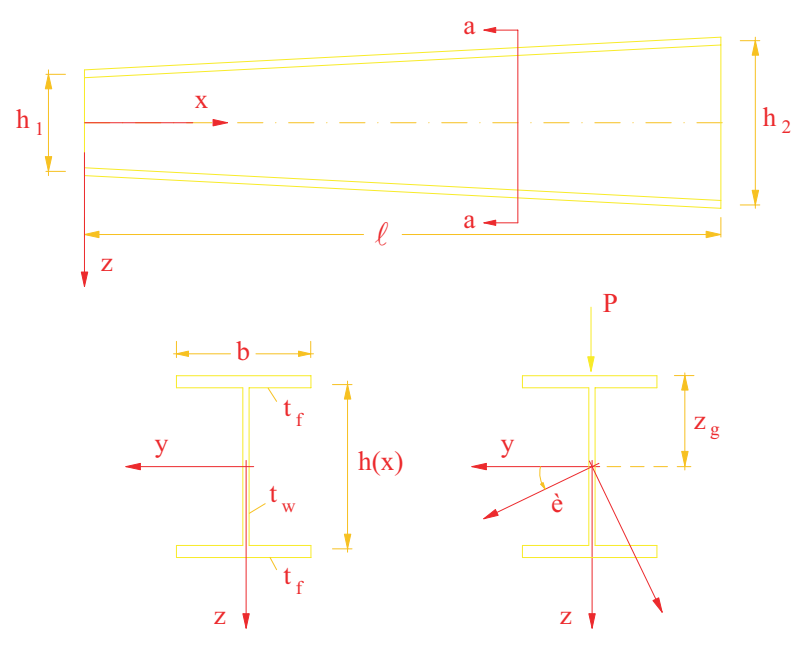

Fig. (1). Geometrical characteristics of a web-tapered I-beam.

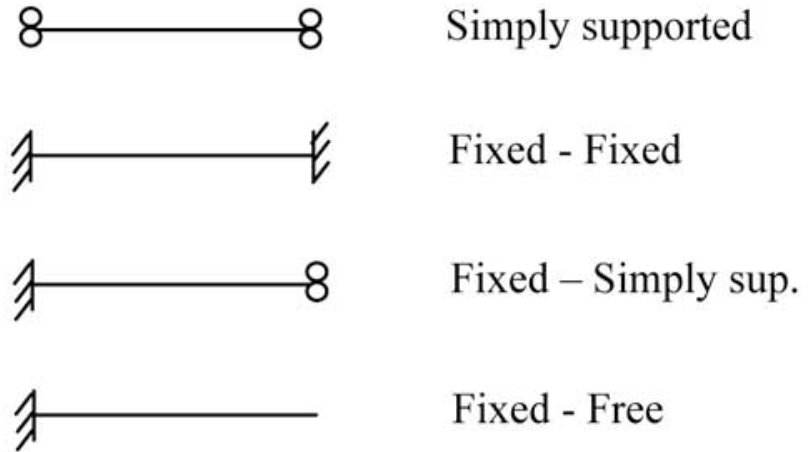

Fig. (2). Boundary conditions for end-rotations of the beam.

The beam is subjected to a transversely applied loading in the form of uniform load $\mathrm{q}$, concentrated load $\mathrm{P}$ or endmoments $M_{1}$ and $M_{2}=\psi M_{1}$. In Fig. (3), one can see a tapered beam subjected to a uniform load $\mathrm{q}$ and the corresponding moment diagram for simply supported boundary conditions regarding bending. The moment distribution along the length of the beam from the above diagram can be expressed as follows

$M(x)=4 M_{0}\left[\frac{x}{\ell}-\left(\frac{x}{\ell}\right)^{2}\right]$

where $\mathrm{M}_{0}$ is the maximum moment value given by.

$M_{0}=q \frac{\ell^{2}}{8}$
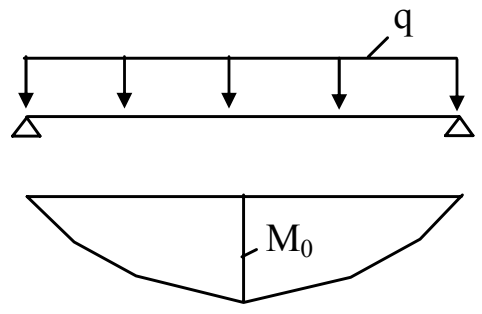

Fig. (3). Moment diagram for uniform load q.

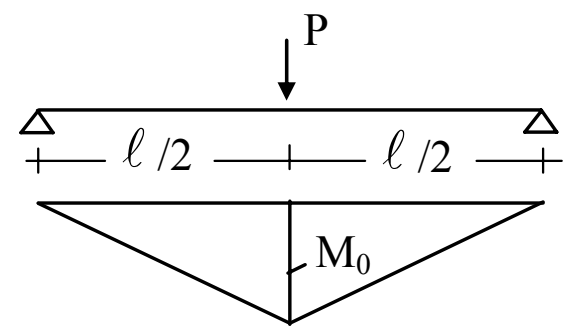

Fig. (4). Moment diagram for concentrated load P.

The beam in Fig. (4) is subjected to a concentrated load P applied at the midlength producing the following moment diagram

In this case, the moment distribution is given by 


$$
\mathrm{M}(\mathrm{x})=\left\{\begin{array}{lc}
2 \mathrm{M}_{0} \frac{\mathrm{x}}{\ell}, & 0<\mathrm{x}<\ell / 2 \\
2 \mathrm{M}_{0}\left(1-\frac{\mathrm{x}}{\ell}\right), & \ell / 2<\mathrm{x}<\ell
\end{array}\right.
$$

where the maximum moment $\mathrm{M}_{0}$ is given by

$$
\mathrm{M}_{0}=\mathrm{P} \frac{\ell}{4}
$$

In Fig. (5), one can see a beam subjected to end moments $\mathrm{M}_{1}$ and $\mathrm{M}_{2}$ producing the corresponding moment diagram

In this case, the moment distribution is given by

$\mathrm{M}(\mathrm{x})=\mathrm{M}_{1}\left[1+(\psi-1) \frac{\mathrm{x}}{\ell}\right]$

where in Fig. (5), $M_{2}=\psi M_{1}$.

As a final case study, we consider the cantilever shown in Fig. (6) that is subjected to a tip load P. The corresponding moment distribution can be expressed as follows

$$
\mathrm{M}(\mathrm{x})=\mathrm{M}_{0}\left(1-\frac{\mathrm{x}}{\ell}\right)
$$

where

$$
\mathrm{M}_{0}=\mathrm{P} \ell
$$

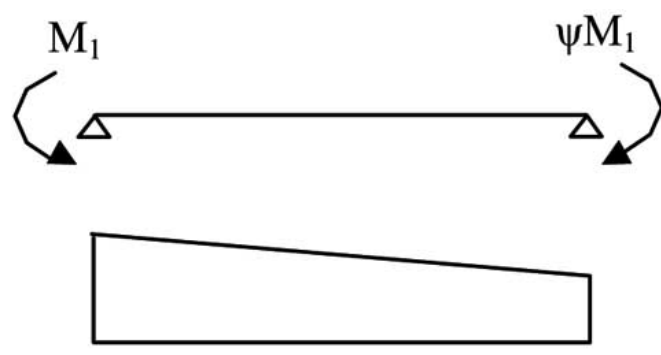

Fig. (5). Moment diagram for end-moments $M_{1}, M_{2}$.

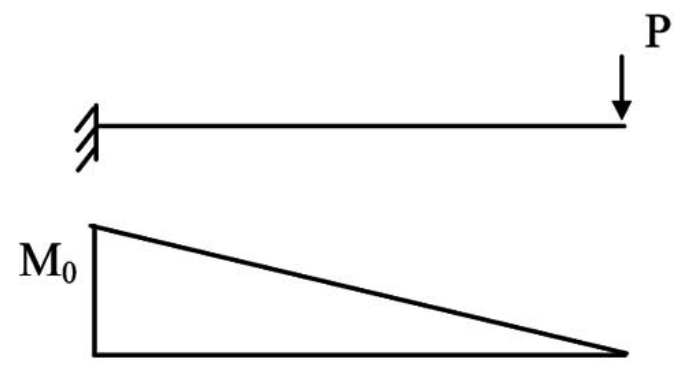

Fig. (6). Moment diagram for tip load P.

The total potential energy $V_{T}$ of the above system is generally given by

$$
\mathrm{V}_{\mathrm{T}}=\mathrm{U}+\Omega
$$

where $\mathrm{U}$ is the strain energy and $\Omega$ is the load potential. The strain energy for twisting (uniform and non-uniform torsion) can be written as

$$
\mathrm{U}=\frac{1}{2} \int_{0}^{\ell} \mathrm{GJ}(\mathrm{x}) \theta^{\prime 2} \mathrm{dx}+\frac{1}{2} \int_{0}^{\ell} \mathrm{EC}_{\mathrm{w}}(\mathrm{x}) \theta^{\prime \prime 2} \mathrm{dx}
$$

where $\mathrm{GJ}(\mathrm{x})$ is the torsional stiffness for uniform torsion (St. Venant) and $\mathrm{EC}_{\mathrm{w}}(\mathrm{x})$ is the warping stiffness for non-uniform torsion. Note that the above terms are not constant since the cross-sectional height is assumed to vary linearly along the length of the beam as given in the following relation

$$
\mathrm{h}(\mathrm{x})=\mathrm{h}_{1}\left(1-\frac{\mathrm{x}}{\ell}\right)+\mathrm{h}_{2} \frac{\mathrm{x}}{\ell}
$$

The cross-sectional properties needed for lateral-torsional buckling of the I-section shown in Fig. (1) can be determined from the following relations

$$
\begin{array}{r}
J(x)=\frac{1}{3}\left[b t_{f}^{3}+h(x) t_{w}^{3}\right] \\
C_{w}(x)=\frac{1}{24} b^{3} h^{2}(x) t_{f}
\end{array}
$$

The load potential $\Omega$ can be determined with the assumption of incompressible axis [16] from the following relation

$\Omega=-\int_{0}^{\ell}\left[\frac{\mathrm{M}^{2}}{\mathrm{EI}_{\mathrm{z}}} \theta^{2}-\mathrm{qz}_{\mathrm{g}} \theta^{2}\right] \mathrm{dx}-\mathrm{Pz}_{\mathrm{g}} \theta_{0}^{2}$

where $\mathrm{EI}_{\mathrm{z}}$ is the flexural stiffness about the weak axis, $\mathrm{z}_{\mathrm{g}}$ is the distance between the point of application of the transverse load $\mathrm{q}$ or $\mathrm{P}$ and the centroid and $\theta_{0}$ is the angle of twist in the position of the concentrated load P, i.e. for $x=\ell / 2$. Thus, after substitution of eq(9) and eq(13) into eq(8), we arrive at the expression of the total potential energy $V_{T}$, in which the only unknown is the angle of twist $\theta(x)$. Note also that secondary effects such as the Wagner effect are negligible for this type of cross-section.

We next approximate the buckled shape of the beam taking into account the boundary conditions for rotation with reference to Fig. (2). Hence, in the simply supported case a suitable approximation can be taken as follows

$\theta(\mathrm{x})=\mathrm{C}_{1} \sin \frac{\pi \mathrm{x}}{\ell}+\mathrm{C}_{2} \sin \frac{2 \pi \mathrm{x}}{\ell}+\mathrm{C}_{3} \sin \frac{3 \pi \mathrm{x}}{\ell}$

Note that the three-term approximation for $\theta(\mathrm{x})$ is proven to be sufficient since the accuracy of the results is less than $0.1 \%$ when keeping more terms. Introducing next the expression for $\theta(\mathrm{x})$ from eq(14) into the final form of the total potential energy eq(8) and after integrating over the length, we obtain an expression of $\mathrm{V}_{\mathrm{T}}$ with respect to the unknown constants $C_{i}(i=1,2,3)$. Finally, we formulate the following eigenvalue problem

$$
\operatorname{det}\left|\frac{\partial^{2} \mathrm{~V}_{\mathrm{T}}}{\partial \mathrm{C}_{\mathrm{i}} \partial \mathrm{C}_{\mathrm{j}}}\right|=0 \quad(\mathrm{i}, \mathrm{j}=1,2,3)
$$

from which the buckling load and the corresponding mode is derived.

Similarly, in the fixed-fixed case we take

$$
\theta(\mathrm{x})=\sum_{\mathrm{i}=1,2,3} \mathrm{C}_{\mathrm{i}}\left(1-\cos \frac{2 \mathrm{i} \pi \mathrm{x}}{\ell}\right)
$$

and for the fixed-free case

$$
\theta(\mathrm{x})=\mathrm{C}_{1}\left(\frac{\mathrm{x}}{\ell}\right)^{2}+\mathrm{C}_{2}\left(\frac{\mathrm{x}}{\ell}\right)^{3}+\mathrm{C}_{3}\left(\frac{\mathrm{x}}{\ell}\right)^{4}
$$


For the fixed-simply supported case we choose a twomode approximation consisting from the corresponding flexural buckling problem, where the buckled shape of the beam is

$$
\begin{aligned}
\theta(\mathrm{x})=\mathrm{C}_{1}\left[\left(\frac{\mathrm{x}}{\ell}\right)^{4}-2.5\left(\frac{\mathrm{x}}{\ell}\right)^{3}+1.5\left(\frac{\mathrm{x}}{\ell}\right)^{2}\right]+ \\
+\mathrm{C}_{2}\left[\sin \frac{\mathrm{kx}}{\ell}-\frac{\mathrm{kx}}{\ell}+\mathrm{k}\left(\cos \frac{\mathrm{kx}}{\ell}-1\right)\right]
\end{aligned}
$$

while, in eq(18), it is $\mathrm{k}=4.493$.

\section{NUMERICAL RESULTS}

Solving the eigenvalue problem in eq(15), we obtain the buckling load and the corresponding mode. Our main concern in this study lies in the cases outlined in the previous section, while results for more complex loading cases and boundary conditions can be similarly derived. In the numerical results presented herein in forms of diagrams, the influence of the web-tapering ratio on the critical load and mode of buckling in steel web-tapered I-beams is thoroughly investigated.

In Fig. (7), one can see the critical load ratio $\mathrm{P}_{\mathrm{cr}} / \mathrm{P}_{\mathrm{cr} 0}$ versus the taper ratio $h_{2} / h_{1}$ for various lengths of a tapered beam made from an IPE-300 profile. The loading consists from a concentrated load $\mathrm{P}$ applied at the midlength with point of application the top flange, i.e. $\mathrm{z}_{\mathrm{g}}=\mathrm{h}_{0} / 2$. The index 0 refers to properties and loads at the midlength of the beam corresponding to the original uniform beam, i.e. IPE-300. The beam is considered simply supported for both bending and twisting.

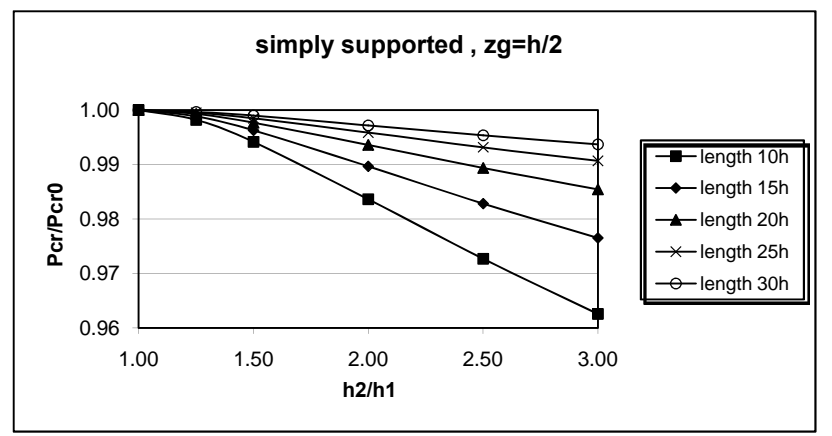

Fig. (7). Critical load ratio $P_{c r} / P_{c r 0}$ versus taper ratio $h_{2} / h_{1}$ for various slenderness ratios of a simply supported beam with concentrated load $\mathrm{P}$ applied at the top flange.

It becomes clear that as the taper ratio increases from $\mathrm{h}_{2} / \mathrm{h}_{1}=1.0$ (uniform beam) to $\mathrm{h}_{2} / \mathrm{h}_{1}=3.0$ (tapered beam), there is a drop of the critical load $\mathrm{P}_{\mathrm{cr}}$, that becomes even more pronounced in the cases of short beams. This drop is about $4 \%$ for $\ell=10 \mathrm{~h}$, while for long beams the drop is less than $1 \%$. It must be noted at this point that although the differences in the critical loads seem to be small, the corresponding differences in the critical load values may be significant depending on the both the taper ratio $h_{2} / h_{1}$ and the length $\ell$. For example, the load $\mathrm{P}_{\text {cro }}$ which used as a reference load, corresponds to a uniform IPE-300 beam with $\mathrm{h}_{1}=\mathrm{h}_{2}=\mathrm{h}_{0}=300$ $\mathrm{mm}$, while if the taper ratio increases to $\mathrm{h}_{2} / \mathrm{h}_{1}=3$, the critical load is computed for a beam with $h_{1}=450 \mathrm{~mm}, h_{2}=150 \mathrm{~mm}$ and $\mathrm{h}_{0}=300 \mathrm{~mm}$.

In Fig. (8), one can see the corresponding diagram for the same beam, which is now considered simply supported for bending and fixed-fixed for twisting. In this case one can see that as the taper ratio increases from $h_{2} / h_{1}=1.0$ (uniform beam) to $h_{2} / h_{1}=3.0$ (tapered beam), there is an increase of the critical load $\mathrm{P}_{\mathrm{cr}}$ up to $6 \%$ for $\ell=10 \mathrm{~h}$, while for longer beams the increase drops to $3.5 \%$.

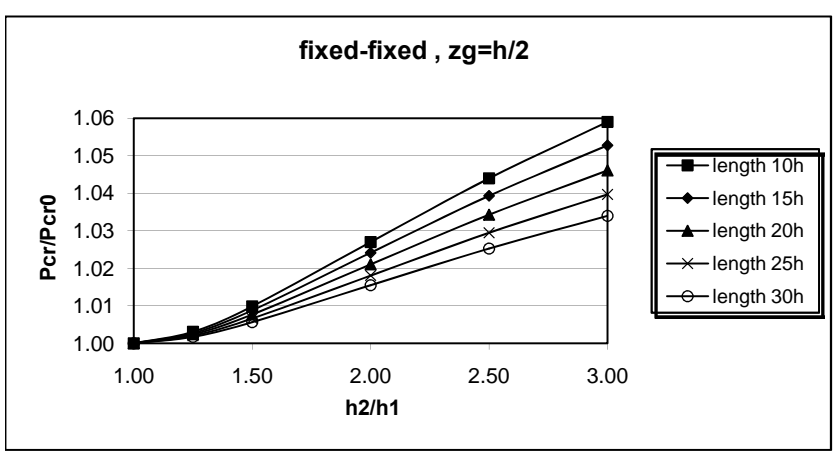

Fig. (8). Critical load ratio $\mathrm{P}_{\mathrm{cr}} / \mathrm{P}_{\mathrm{cr} 0}$ versus taper ratio $\mathrm{h}_{2} / \mathrm{h}_{1}$ for various slenderness ratios of a fixed-fixed beam with concentrated load $\mathrm{P}$ applied at the top flange.

Similarly in Fig. (9), one can see the corresponding to the above diagram, where the beam is considered simply supported for bending and fixed-simply supported for twisting.

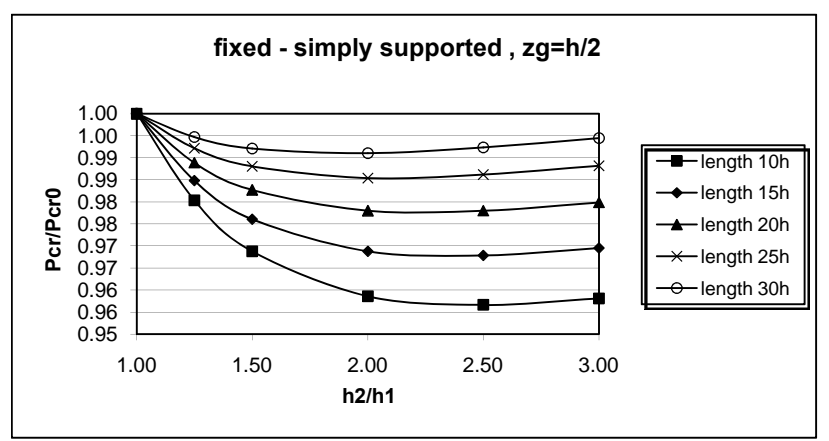

Fig. (9). Critical load ratio $\mathrm{P}_{\mathrm{cr}} / \mathrm{P}_{\mathrm{cr} 0}$ versus taper ratio $\mathrm{h}_{2} / \mathrm{h}_{1}$ for various slenderness ratios of a fixed-simply supported beam with concentrated load $\mathrm{P}$ applied at the top flange.

In this case one can see that as the taper ratio increases from $\mathrm{h}_{2} / \mathrm{h}_{1}=1.0$ (uniform beam) to $\mathrm{h}_{2} / \mathrm{h}_{1}=3.0$ (tapered beam), there is a drop of the critical load $\mathrm{P}_{\mathrm{cr}}$ up to $4.5 \%$ for $\ell=10 \mathrm{~h}$. The maximum drop occurs for taper ratios in the range of $\mathrm{h}_{2} / \mathrm{h}_{1}=2.0$ and $\mathrm{h}_{2} / \mathrm{h}_{1}=2.5$, while for higher taper ratios this effect is reversed.

Next, we examine the same simply supported tapered beam where the concentrated load $\mathrm{P}$ is now applied at the centroid, i.e. $\mathrm{z}_{\mathrm{g}}=0$. From Fig. (10), it becomes clear that as the taper ratio increases from $h_{2} / h_{1}=1.0$ to $h_{2} / h_{1}=3.0$, there is a drop of the critical load $\mathrm{P}_{\mathrm{cr}}$, that becomes even more pronounced in the cases of short beams. This drop is now 3\% for $\ell=10 \mathrm{~h}$, while for long beams the drop is less than $1 \%$. In 
Fig. (11), one can see the corresponding diagram for the same beam, which is considered fixed-fixed for twisting. As the taper ratio increases from $h_{2} / h_{1}=1.0$ to $h_{2} / h_{1}=3.0$, the corresponding increase of the critical load $\mathrm{P}_{\mathrm{cr}}$ is up to $4.5 \%$ for $\ell=10 \mathrm{~h}$, while for longer beams the increase drops to $2.8 \%$.

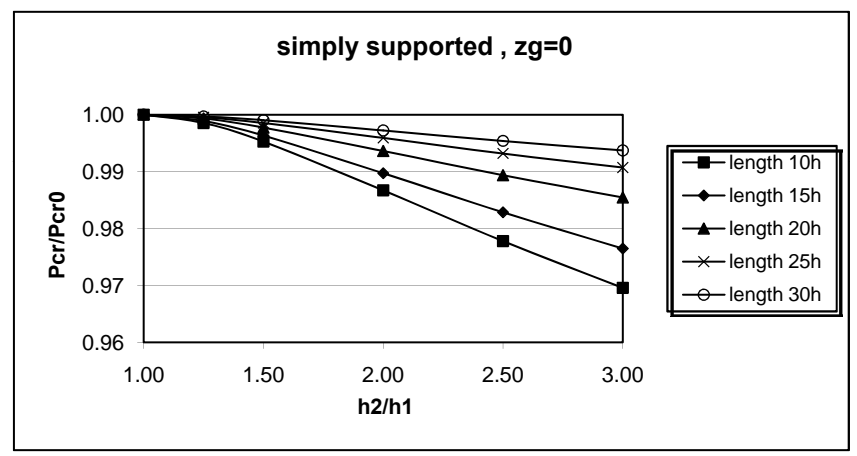

Fig. (10). Critical load ratio $P_{c r} / P_{c r 0}$ versus taper ratio $h_{2} / h_{1}$ for various slenderness ratios of a simply supported beam with concentrated load P applied at the centroid.

In Fig. (12), we show the corresponding to the above diagram, where the beam is considered fixed-simply supported for twisting.

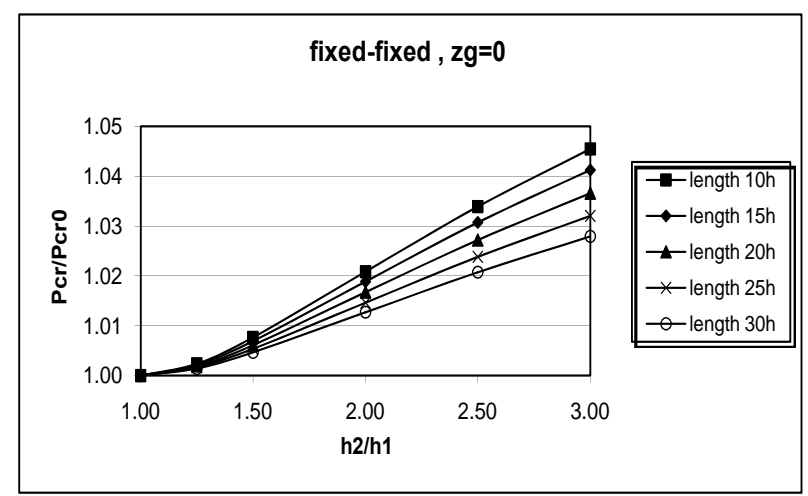

Fig. (11). Critical load ratio $P_{c r} / P_{c r 0}$ versus taper ratio $h_{2} / h_{1}$ for various slenderness ratios of a fixed-fixed beam with concentrated load $\mathrm{P}$ applied at the centroid.

In this case one can see that as the taper ratio increases from $h_{2} / h_{1}=1.0$ to $h_{2} / h_{1}=3.0$, there is a drop of the critical load $\mathrm{P}_{\text {cr }}$ up to $3 \%$ for $\ell=10 \mathrm{~h}$. The maximum drop occurs again for taper ratios $h_{2} / h_{1}=2.0$ to 2.5 , while for higher taper ratios this effect is reversed, as expected. In Figs (13 to 15) are shown the corresponding critical load versus taper ratio diagrams for various lengths and boundary conditions of the beam with concentrated load P applied at the bottom flange, i.e. $\mathrm{z}_{\mathrm{g}}=-\mathrm{h} / 2$. The buckling behavior observed in these diagrams follows the pattern established previously with corresponding differences in the critical loads less than $3 \%$. From a comparison between Figs (7 to 15) the stabilizing effect of the load position $\mathrm{zg}_{\mathrm{g}}$ is verified and the effect of the taper ratio on the critical load is well established for various boundary conditions.

As a second case study, we examine the simply supported tapered beam subjected to a uniform load $\mathrm{q}$ applied at the centroid, i.e. $\mathrm{z}_{\mathrm{g}}=0$. From Fig. (16), we can see that as the taper ratio increases from $\mathrm{h}_{2} / \mathrm{h}_{1}=1.0$ to 3.0 , there is a drop of the critical load $\mathrm{q}_{\mathrm{cr}}$, which becomes more pronounced in the cases of short beams. This drop is $3.3 \%$ for $\ell=10 \mathrm{~h}$, while for long beams the drop is less than $1 \%$.

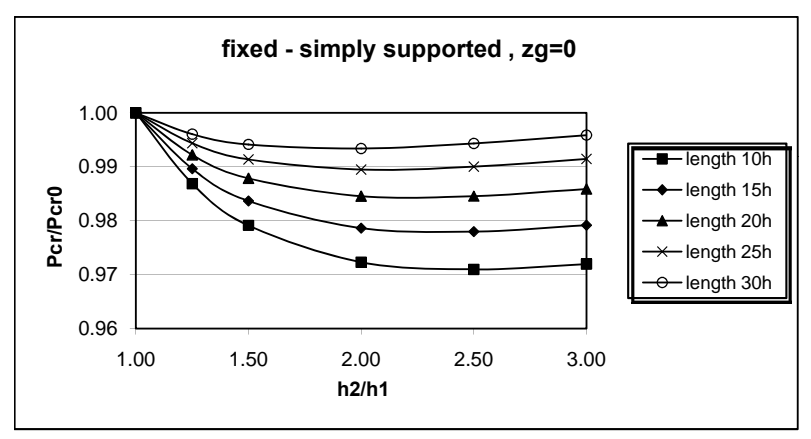

Fig. (12). Critical load ratio $P_{c r} / P_{c r 0}$ versus taper ratio $h_{2} / h_{1}$ for various slenderness ratios of a fixed-simply supported beam with concentrated load $\mathrm{P}$ applied at the centroid.

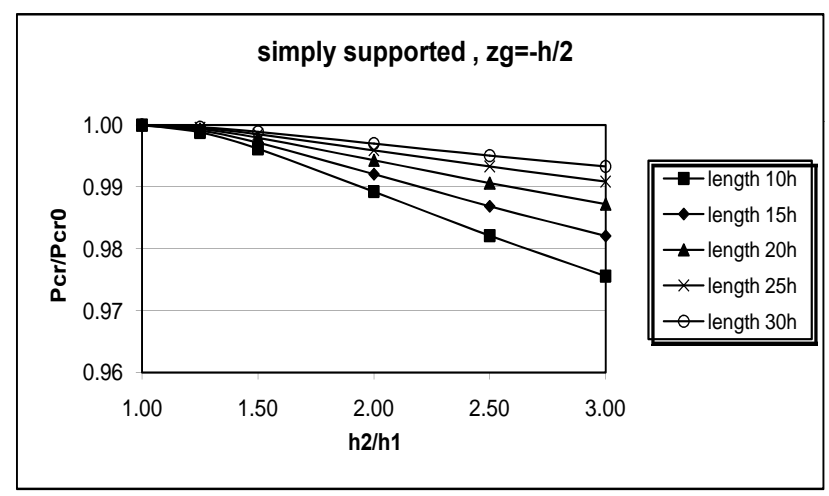

Fig. (13). Critical load ratio $P_{c r} / P_{c r 0}$ versus taper ratio $h_{2} / h_{1}$ for various slenderness ratios of a simply supported beam with concentrated load $\mathrm{P}$ applied at the bottom flange.

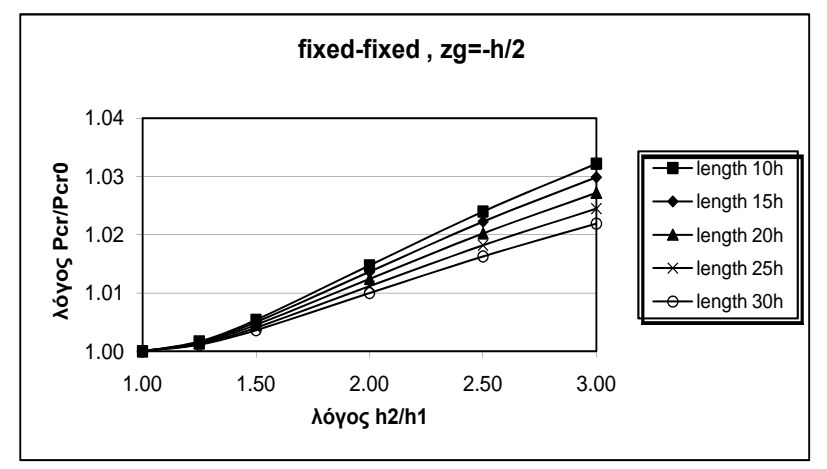

Fig. (14). Critical load ratio $P_{c r} / P_{c r 0}$ versus taper ratio $h_{2} / h_{1}$ for various slenderness ratios of a fixed-fixed beam with concentrated load $\mathrm{P}$ applied at the bottom flange.

Comparing Figs (10 and 16) we see that there is a slight increase in the drop of the critical load and hence, the distributed load affects more the buckling behavior compared to the concentrated load. 


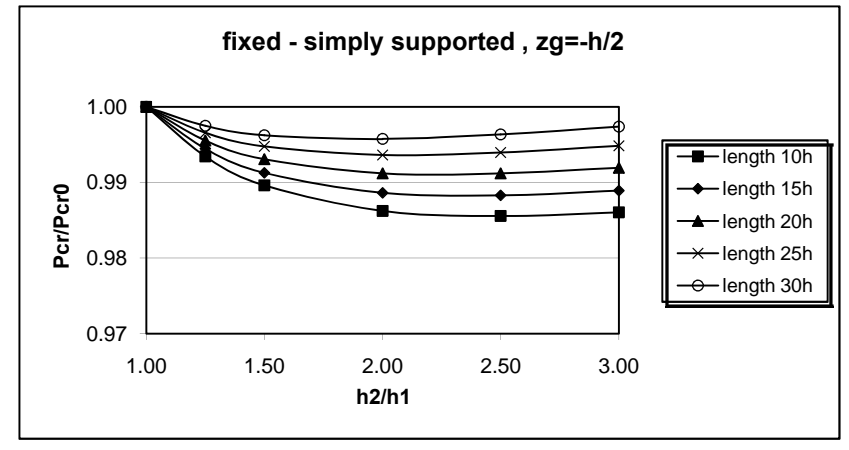

Fig. (15). Critical load ratio $P_{c r} / P_{c r 0}$ versus taper ratio $h_{2} / h_{1}$ for various slenderness ratios of a fixed-simply supported beam with concentrated load $\mathrm{P}$ applied at the bottom flange.

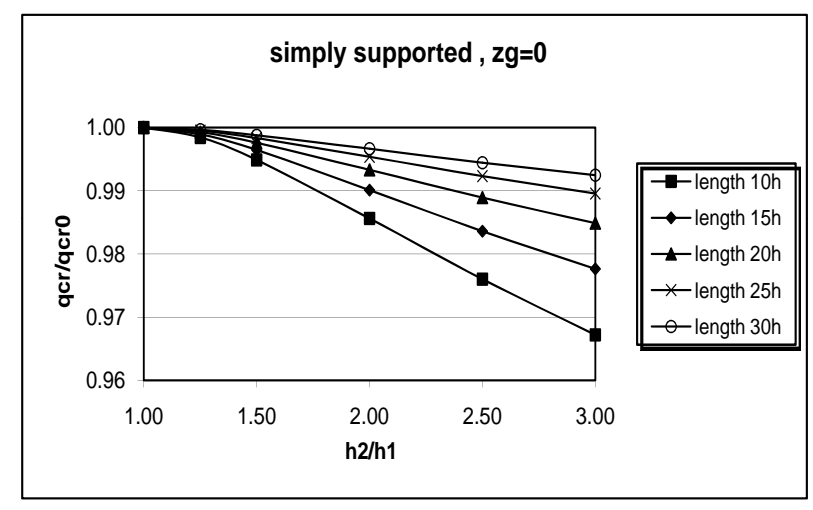

Fig. (16). Critical load ratio $\mathrm{q}_{\mathrm{cr}} / \mathrm{q}_{\mathrm{cr} 0}$ versus taper ratio $\mathrm{h}_{2} / \mathrm{h}_{1}$ for various slenderness ratios of a fixed-simply supported beam with uniform load $\mathrm{q}$ applied at the centroid.

In Fig. (17) we show the effect of the twisting boundary conditions on the critical load for a beam simply supported for bending with $\mathrm{z}_{\mathrm{g}}=0, \ell=10 \mathrm{~h}_{0}$ and various values of the taper ratio.

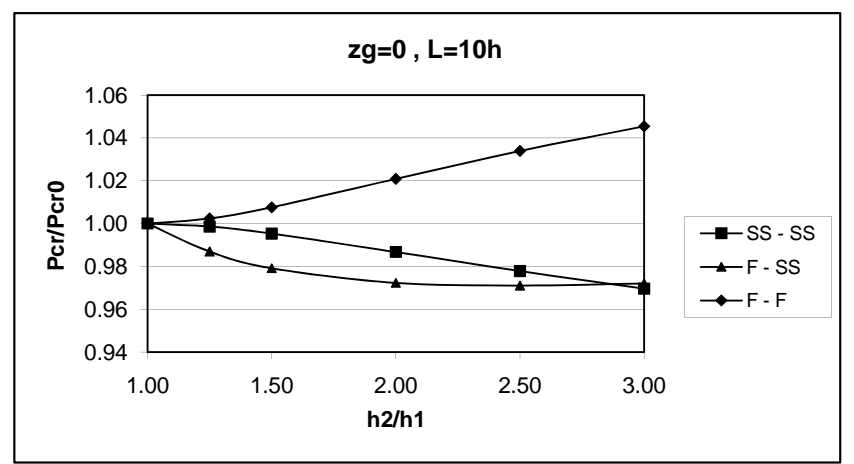

Fig. (17). Critical load ratio $P_{c r} / P_{c r 0}$ versus taper ratio $h_{2} / h_{1}$ for various support conditions of a tapered beam with concentrated load $\mathrm{P}$ applied at the centroid.

It becomes clear that a fixed condition tends to stabilize the tapered beam and the critical load increases with the increase of the taper ratio (see fixed-fixed case) whereas in the cases with one or two simple supports the critical load drops.
As a third case study, we examine the simply supported tapered beam subjected to end moments $\mathrm{M}_{1}$ and $\mathrm{M}_{2}$. In Fig. (18), one can see the critical load values versus taper ratio for a beam with length $\ell=10 \mathrm{~h}$ and various values of the endmoment ratio $\psi$. It is clear that as the taper ratio increases from $\mathrm{h}_{2} / \mathrm{h}_{1}=1.0$ to 3.0, there is a significant drop of the critical moment $\mathrm{M}_{\mathrm{cr}}$ with maximum value $12 \%$ for $\psi=-0.5$, while for $\psi=1$ the drop is only $4 \%$.

In Fig. (19), one can see the same as above diagram for the fixed-fixed case. We can see that as the taper ratio increases from $h_{2} / h_{1}=1.0$ to 3.0 , the critical moment $M_{\text {cr }}$ also increases with maximum value $6.5 \%$ for $\psi=-1$, while for other values of $\psi$ the increase in almost $5.2 \%$.

As a final case study, we examine the tapered cantilever subjected to a tip load P applied at the centroid. In Fig. (20), one can see the critical load values versus taper ratio for a cantilever with various length values. In this case, as the taper ratio increases from $h_{2} / h_{1}=1.0$ to 3.0 , there is a significant increase of the critical load $\mathrm{P}_{\text {cr }}$ with maximum value $34 \%$ for $\ell=3 \mathrm{~h}$, while for longer lengths the drop decreases to $22 \%$.

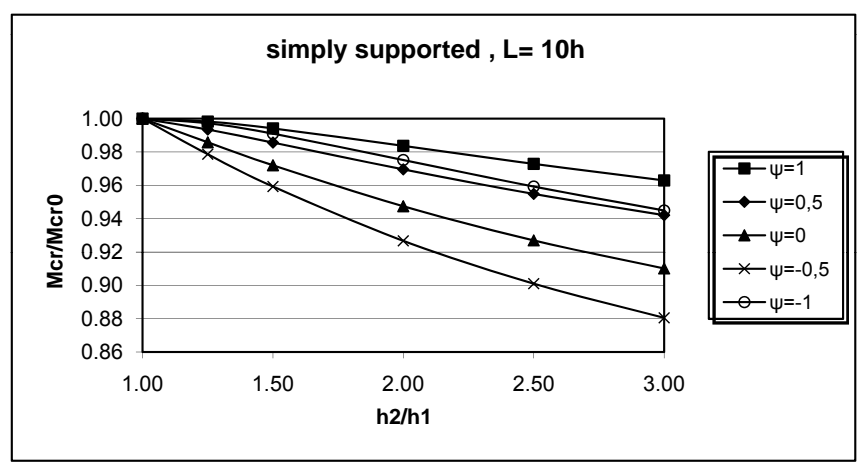

Fig. (18). Critical moment ratio $M_{c r} / M_{c r 0}$ versus taper ratio $h_{2} / h_{1}$ for various end-moment ratios of a simply-supported tapered beam.

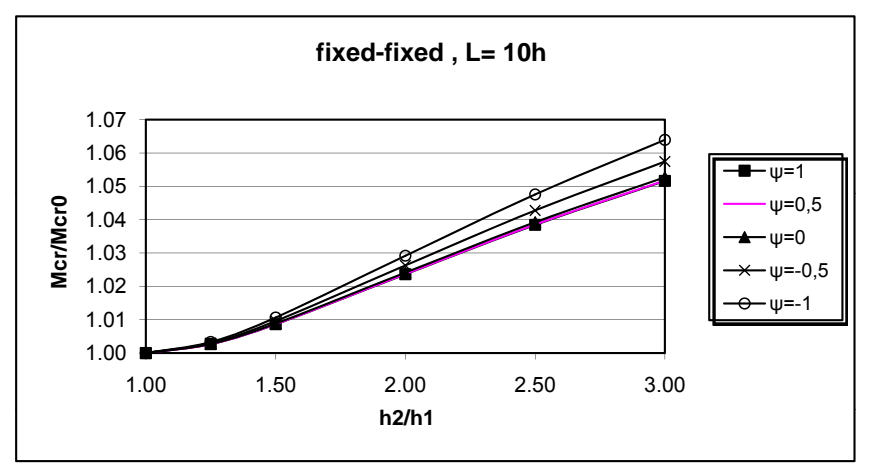

Fig. (19). Critical moment ratio $M_{c r} / M_{c r 0}$ versus taper ratio $h_{2} / h_{1}$ for various end-moment ratios of a fixed-fixed tapered beam.

In Fig. (21), one can see a comparison between the critical loads (moments) for lateral-torsional buckling of an IPE and a wide-flange HEB beam. The wide flanges have a stabilizing effect on the critical load since the warping stiffness of the cross-section increases significantly. This effect seems not to be influenced by the web-tapering since the drop of the critical load is almost the same in both cases. 


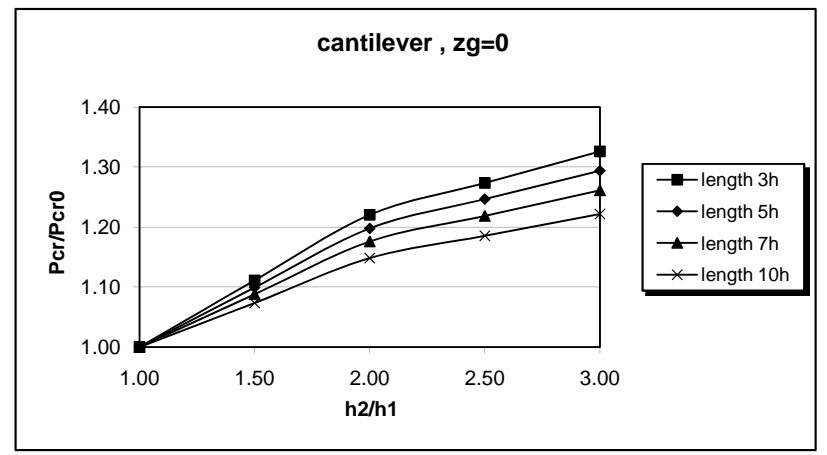

Fig. (20). Critical load ratio $P_{c r} / P_{c r 0}$ versus taper ratio $h_{2} / h_{1}$ for various slenderness ratios of a cantilever with a tip load $\mathrm{P}$ applied at the centroid.

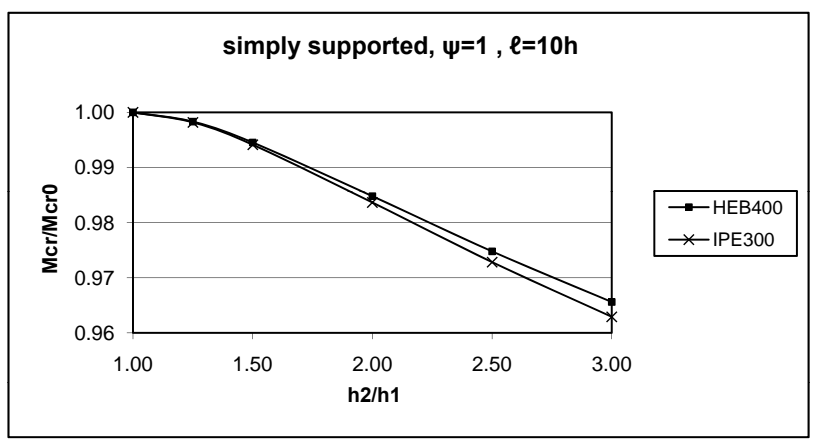

Fig. (21). Critical moment ratio $M_{c r} / M_{c r 0}$ versus taper ratio $h_{2} / h_{1}$ for tapered beams made from IPE and HEB profiles.

The above results obtained via the energy method correlate well, where applicable, with the analytical and experimental results presented by Kitipornchai \& Trahair [3] with a maximum deviation $1.2 \%$ regarding the analytical results and $2.3 \%$ regarding the experimental ones. Fine agreement is also observed with the results in form of graphs given by Bradford [10] for beams with unequal end-moments $M$ at the larger and $\psi \mathrm{M}$ at the smaller end. The maximum deviation with the results of this study was $1.9 \%$.

\section{FINITE ELEMENT ANALYSIS}

Some characteristic cases of the above studies have also been validated via the Finite Element Method. For this purpose, the Algor FEA commercial code [17] has been employed for linear buckling analysis. Such a detailed FE model of an I-beam with taper ratio $\mathrm{h}_{2} / \mathrm{h}_{1}=2.0$ build up from an original profile IPE-300 is shown in Fig. (22). The model consists of 1200 3-D oriented quadrilateral plate elements that are employed to model the flanges and the web of the tapered beam. More specifically, the lateral-torsional buckling mode of the above model subjected to a uniform load q is shown in Fig. (23) for simply supported boundary conditions. In Fig. (24), one can see the buckling mode for a tapered cantilever model with taper ratio $\mathrm{h}_{2} / \mathrm{h}_{1}=1.5$ consisting from 600 elements which is subjected to a tip load P applied at the top flange. It is found that the analytical results presented herein correlate well with the corresponding FEA results with a maximum error less than $0.2 \%$.

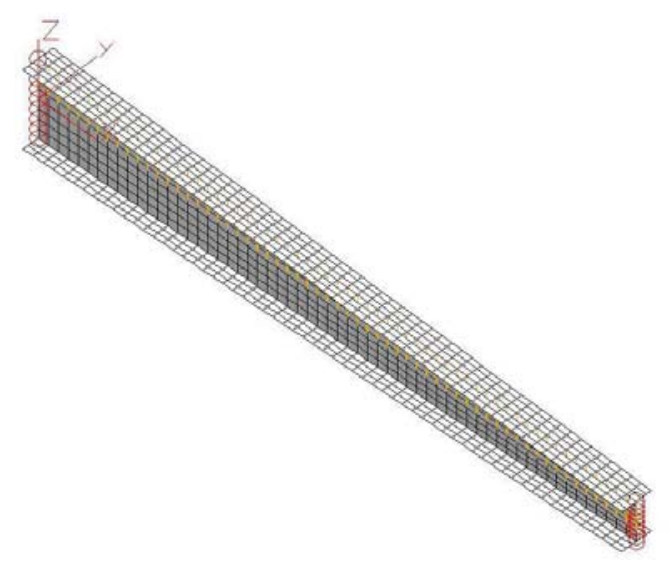

Fig. (22). FE model of a tapered beam made from an IPE-300 profile.

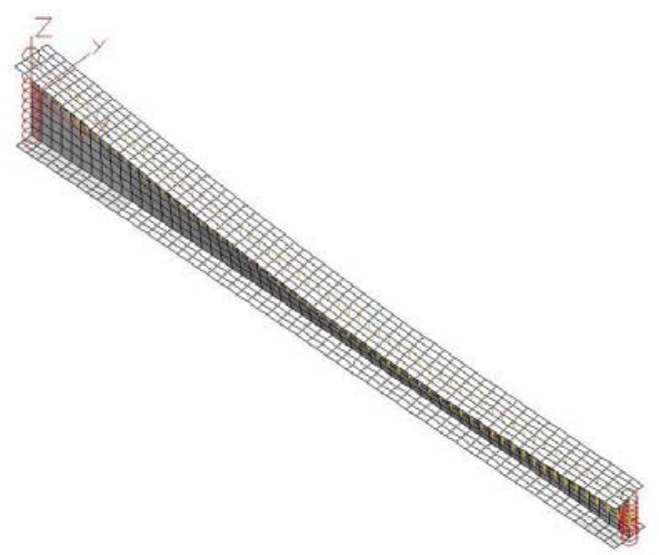

Fig. (23). Lateral-torsional buckling of a simply sup-ported tapered beam under uniform load $\mathrm{q}$.

Note at this point that employment of the FE Method for lateral-torsional buckling always requires a detailed model of the beam with special care paid to boundary conditions in order to represent correctly bending, twisting and warping at the supported ends. On the other hand, the technique presented herein is much simpler regarding computational effort, while the boundary conditions are employed by a proper selection of the moment and buckling mode shape functions.

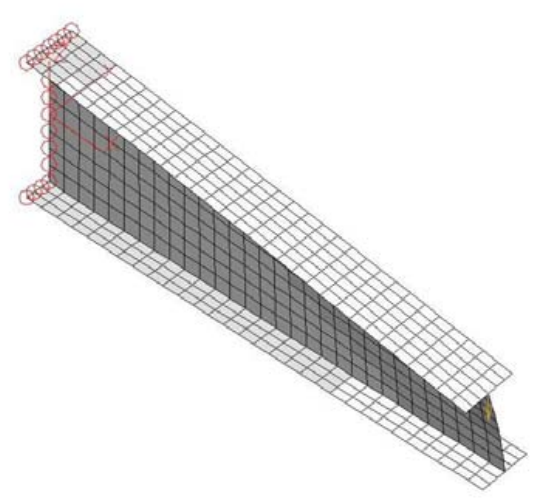

Fig. (24). Lateral-torsional buckling of a tapered IPE cantilever under tip load $\mathrm{P}$. 


\section{SUMMARY AND CONCLUSIONS}

In this study, the elastic buckling behavior of steel webtapered I-beams by means of determining the corresponding elastic critical moment for lateral-torsional buckling. This critical moment can be used for the determination of the corresponding member strength. More specifically, the influence of the taper ratio and cross-sectional geometry, the boundary conditions and the loading type on the stability of non-uniform steel members that are subjected to bending loads is thoroughly investigated.

The most important conclusions that can be drawn from this study are:

- The lateral-torsional buckling of web-tapered I-beams is always affected by the web-tapering ratio and the slenderness ratio.

- Depending on the taper ratio and the slenderness ratio, the critical buckling load can be determined with reference to the original profile from which the tapered beam is manufactured.

- As the taper ratio increases, the torsional buckling load decreases slightly for simply supported beams, while for fixed boundary conditions this effect is strongly reversed.

- The influence of the taper ratio on the critical load of web-tapered I-beams is proven to be significant especially in the case of cantilevers and must be taken into when designing such members against buckling.

- The technique presented herein is much simpler regarding computational effort, while the boundary conditions are employed by a proper selection of the moment and buckling mode shape functions.

\section{REFERENCES}

[1] T. Galambos, Ed., Guide to Stability Criteria for Metal Structures, Wiley: New York, 1988

[2] G. Ballio, and F. M. Mazzolani, Ed., Theory and Design of Steel Structures, Chapman and Hall: London, 1983.

[3] S. Kitipornchai, and N. S. Trahair, "Elastic stability of tapered Ibeams", J Struct Div ASCE, vol. 98, no. ST3, pp. 713-728, 1972.

[4] D. J. Frazer, "Design of tapered member portal frames", Construct. Steel. Res., vol. 3, no. 3, pp. 20-26, 1983.

[5] Z. Mendera, Buckling Strength of Tapered Steel Beams, Stahlbau, Ernst \& Sohn, Berlin: 1995, vol. 64, no. 4.

[6] J. Ermopoulos, "Buckling of tapered bars under stepped axial loads", J. Struct. Eng. ASCE, vol. 112, no. 6, pp. 1346-1354, 1986.

[7] J. Ermopoulos, "Slope-deflection method and bending of tapered bars under stepped loads", Construct. Steel Res., vol. 11, no. 2, pp. 121-141, 1988.

[8] J. Ermopoulos, "Equivalent buckling length of non-uniform members", Construct. Steel Res., vol. 42, no. 2, pp. 141-158, 1997.

[9] J. Ermopoulos, "Buckling length of nonuniform members under stepped axial loads", Int. J. Comput. Struct., vol. 73, pp. 573-582, 1999.

[10] M. A. Bradford, "Stability of tapered I-beams", Construct. Steel Res., vol. 9, no. 3, pp. 195-206, 1988.

[11] A. Andrade, D. Camotim, and P. B. Dinis, "Lateral-torsional buckling of singly symmetric web-tapered thin-walled I-beams", Comput. Struct., vol. 85, no. 17-18, pp. 1343-1359, 2007.

[12] L. Zhang, and G. S. Tong, "Lateral-torsional buckling of webtapered I-beams: A new theory", Construct. Steel Res., vol. 64, no. 12, pp. 1379-1393, 2008.

[13] A. Khelil, and B. Larue, "Simple solution for the flexural-torsional buckling of laterally restrained I-beams", Eng. Struct., vol. 30, no. 10, pp. 2923-2934, 2008.

[14] S. P. Timoshenko, and J. M. Gere, Ed., Theory of Elastic Stability, McGraw-Hill: New York, 1961.

[15] Eurocode 3, Design of steel structures. Part 1.1: General rules and rules for buildings. EN 1993-1-1. European Committee for Standardization: Brussels, 2004.

[16] A. Chajes, Ed., Principles of Structural Stability, Englewood Cliffs: Prentice-Hall Inc, New Jersey, 1974.

[17] C. C. Spyrakos, and I. G. Raftoyiannis, Ed., Linear and Non-linear Finite Element Analysis in Engineering Practice: Algor Publishing Division: Pittsburgh, PA, 1997. 